\title{
On the Relationship between Digestive Gases and Buoyancy in Sharks
}

\author{
Erich K Ritter ${ }^{1,2 *}$ \\ ${ }^{1}$ Department of Mathematics \& Statistics, University of West Florida, USA \\ ${ }^{2}$ Shark Research Institute, USA \\ *Corresponding author: Erich K Ritter, Department of Mathematics \& Statistics, University of West Florida11000 University Parkway, Pensacola, \\ Florida 32514, USA
}

Submission: 㘹 June 21, 2018; Published: 監 July 06, 2018

\begin{abstract}
Digestive gases, which naturally occur inside marine animals, affect their buoyancy. Following Boyle's law, any change in hydrodynamic pressure leads to a change in the volume of such gases. Therefore during an ascent from deep to shallow waters, decompressing gases can lead to a positive effect on buoyancy. It may be necessary to release these gases into the surrounding water for an animal to control its depth effectively. Here, two videos are presented on how sharks can get rid of excessive digestive gases and it is discussed how these observations fit with the general understanding of digestive gas production and buoyancy control.
\end{abstract}

Keywords: Boyle's law; Compression; Decompression; Digestive gas; Shark

\section{Introduction}

When food is broken down during digestion, digestive gases are a common by product in the stomach and intestine. The production of digestive gases is dependent on the amount and composition of the food consumed. Additionally, in aquatic animals, including teleosts, the volume of gas produced is dependent not only on food composition but is also dependent on hydrodynamic pressure which is directly correlated with the depth of the organism beneath the water's surface. As hydrostatic pressure increases, the volume of digestive gases compresses, and vice versa. This co-dependency between gas volume and water pressure is referred to as Boyle's law $[1,2]$ and can be expressed as

$$
\mathrm{p} 1 * \mathrm{~V} 1=\mathrm{p} 2 * \mathrm{~V} 2
$$

Where $\mathrm{p} 1$ and $\mathrm{p} 2$ reflect said hydrostatic pressure, and V1 and V2 refer to the corresponding gas volumes. A similar albeit less prominent effect can also be accomplished through a change of water temperature. The warmer the water gets, the more the gas volume increases, and vice versa. Since digestive gases accumulate inside a teleost's stomach and intestines as long as food is broken down, an ascent by the teleost causes the volume of intestinal gas to increase, which can reach a level where pressure reduction is paramount and excessive gases are released into the surrounding water. This is especially important should the teleost then plan to level out [3]. Although the anal opening seems to be the logical body opening for releasing digestive gases, the oral cavity can also be used.

The production of digestive gases has primarily been studied among teleosts, but it can be assumed that these observations also hold true for sharks where biochemical digestion occurs in a similar fashion [4]. Nevertheless, the lack of studies on the production of digestive gases among sharks is rather surprising, considering the amount of studies done on digestion itself [5-7]. There is only one published reference suggesting that digestive gases might be common in sharks. This study was performed on sandtiger sharks, Carcharias taurus, who retain some of these gases for buoyancy purposes $[8,9]$. This gas retention allows them to hover without any actual forward motion. Sandtiger sharks are also able to actively increase the gas content within their stomachs by ascending to the surface and gulping air before descending to their preferred depth. Due to the increased hydrostatic pressure when diving, gulping air sometimes means that a sandtiger likely may overinflate at the surface to then properly compensate at the chosen depth. among teleosts [3] to hover without actual forward motion. Sandtiger sharks are also able to actively increase the gas content within their stomachs by ascending to the surface and gulping air before descending to their preferred depth. Due to the increased hydrostatic pressure when diving, gulping air sometimes means that a sandtiger likely may overinflate at the surface to then properly compensate at the chosen depth. Gulping air is already a well-established phenomenon among teleosts [3].

Sandtigers are currently the only known shark species that hovers; other species either lay on the bottom, or have to permanently swim, at least slowly, only interrupted by gliding phases [10]. Bottom oriented, sedentary shark species are more negatively buoyant than free swimming species. For free swimming [pelagic] sharks, 
buoyancy is usually maintained by rather large livers containing high levels of fatty substances, like squalene [11]. Nevertheless, even among pelagic sharks, digestive gases need to be dealt with when neutral buoyancy is desired and striving for such equilibrium seems paramount should an animal prefer to occupy a certain depth. But as soon as a shark starts to feed, buoyancy is affected again and adjustments are required once more.

The amount of gas produced during digestion largely depends on the amount and type of food consumed. Intervals between food intake among and between shark species vary, ranging from daily feeding to food intake at longer intervals which may extend to several weeks [12-14]. Sharks commonly encounter a rather wide range of prey, but it is generally accepted that their food base is mostly carnivorous, with a focus on those teleosts that are high in lipids and proteins $[4,13,15]$. High levels of lipids prolong gastric evacuation [16], thus extending nutrient absorption. The same effect can be reached by moving into colder water to slow digestion down $[4,17]$.

In this report, two observations among sharks are described where digestive gases are released through the oral and anal openings, respectively, and these are discussed in the context of current knowledge on digestive gas production and buoyancy control among free-swimming sharks.

\section{Materials and Methods}

Gas release through the oral cavity of an oceanic white tip shark, Carcharhinus longimanus, was videotaped off the coast of Egypt, in the Red Sea. The shark was milling at a depth of about $20 \mathrm{~m}$ and was observed for several minutes during which time it did not make any attempt to ascend. When the shark finally did swim upwards towards the surface, it did so quickly and in a vertical manner. It took no more than a few seconds for the shark to reach the same level as the videographer who was filming from close to the surface. As soon as the shark levelled out, immediate gas release through its right gill slits occurred (Figure 1). The release happened rapidly on reaching its new depth and took less than one second. The shark was estimated to be around $2 \mathrm{~m}$ in length, a size that enabled it to easily access all its common food sources which primarily consist of fish [18]. The water temperature at the time of video recording was 27 ${ }^{\circ} \mathrm{C}$. The second observation involved a tiger shark, Galeocerdo $\mathrm{Cu}-$ vier, releasing gases through its cloaca (Figure 2). The shark was videotaped off the Coast of Beqa Island, part of the Fiji archipelago, and was cruising for about 15 minutes in constant visual range at the same depth as the videographer of about $18 \mathrm{~m}$. The shark did not change its speed or body position while releasing the bubbles through its cloaca. The length of the animal was estimated to be around $4 \mathrm{~m}$, which is also well within its range for consumption of all the foods commonly associated with this species [18]. The water temperature was $25{ }^{\circ} \mathrm{C}$. The videos were respectively taken with a Sony HC-9 video camera in Sea Tool housing, at 1080i high definition and a frame rate of $30 \mathrm{fps}$, and a Go Pro 4 with the same frame rate and definition. Both videos were transferred onto Final Cut Pro $\mathrm{X}$ from Apple ${ }^{\odot}$ for detailed observation. A quantitative estimation of the released gases could not be done.

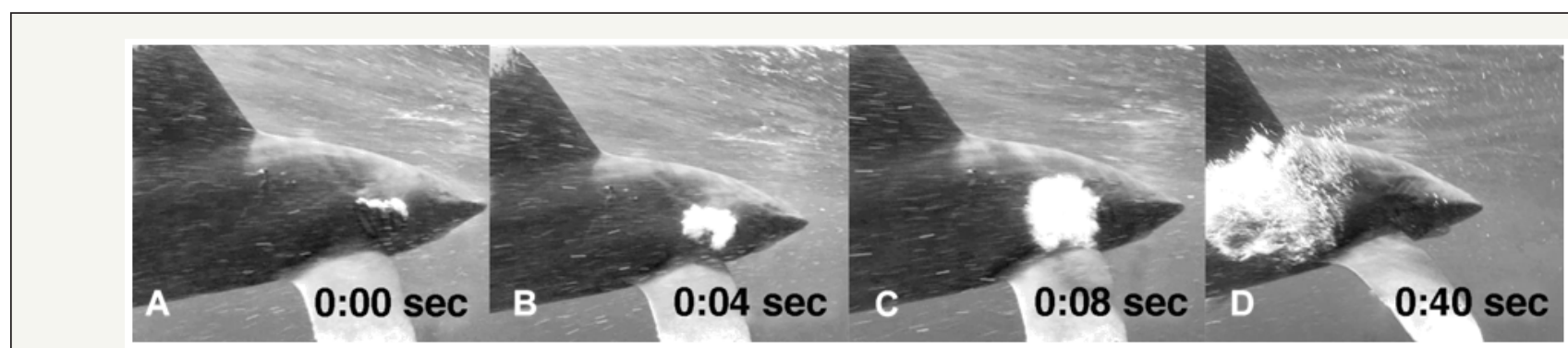

Figure 1: Digestive gases released through the right gill slits. Numbers refer to fraction of seconds.

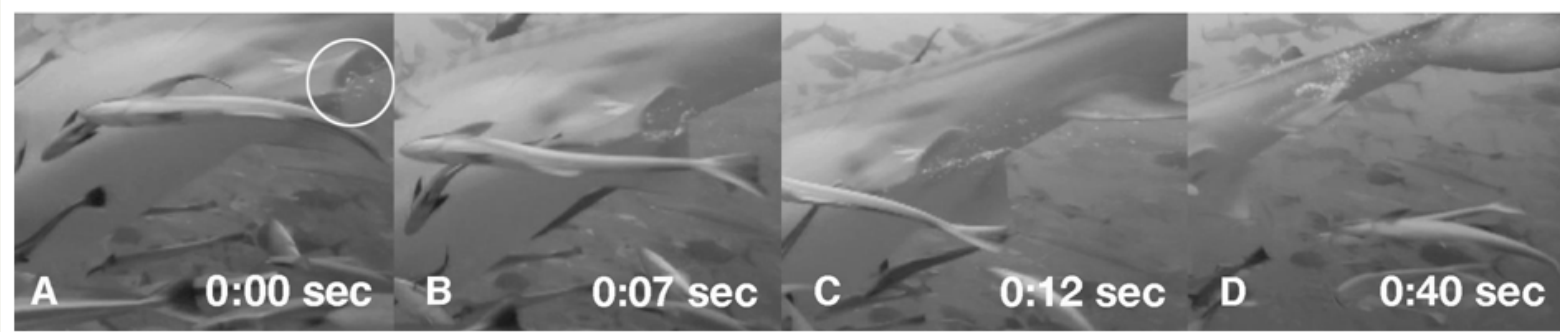

Figure 2: Digestive gases released through the anal opening (circle). Numbers refer to fraction of seconds.

\section{Results and Discussion}

The oceanic whitetip shark released its gases through the right gill slits in one very quick attempt, while the gas release through the cloaca of the tiger shark happened slowly, consisting of a number of small bubbles. The immediate gas release in the first case was likely triggered by the quick ascent of the shark from about $20 \mathrm{~m}$ to close to the surface, causing a drop of hydrostatic pressure from approximately $3 \mathrm{~atm}$ to $1 \mathrm{~atm}$. Depending on the initial amount of gases stored, the sudden increase in volume could cause a quick release which thus appeared rather instantaneous in this case. This is in contrast with the observed gas release from the tiger shark. Here, 
neither a decrease in hydrodynamic pressure nor a negative tilt of its body occurred, thus a rather small chain of bubbles appeared without any visual volume expansion.

\section{Developing and storage of digestive gases}

Food breakdown in the gastric system depends on a variety of factors, ranging from amount of food intake, food composition, digestion rate to gastric acid release and water temperature. These and other factors strongly influence the gastric evacuation rates $[19,20]$. Digestion of foods is a continuous process along the entire gastrointestinal tract, starting with the oesophagus, leading into either a siphonal or straight stomach [21,22], followed by the proximal and spiral intestine, and ending in the colon [23]. Although the orobranchial area of a shark plays a role in digestion, it has primarily a mechanical function, hence it is the stomach where biochemical digestion normally begins, especially the breakdown of proteins [21]. Protein breakdown is primarily enabled through proteases like pepsin which is made from its precursor pepsinogen [22]. Gastric acids facilitate digestion by providing the optimal $\mathrm{pH}$ for digestive enzyme function. Food breakdown products are then transported through to the intestines under the control of the motile actions of the stomach for further digestion. The bile and pancreatic ducts are located in the proximate area of the intestine, and are responsible for polymer digestion [4], whereas the distal area, the spiral intestine with its increased surface, breaks down and absorbs many nutrients. Since food breakdown occurs along the entire gastric system, digestive gases can be produced at any point in the system. Therefore gas pockets of different sizes are likely present throughout the entire digestive tract.

\section{Center of gravity and buoyancy imbalance}

Free swimming sharks are considered to be buoyant to varying degrees $[24,25]$ however the shark's center of gravity can be affected by the amount of food intake in relation to the size of the shark. Some known species have a daily food intake corresponding to $1 \%$ to $2 \%$ of their body weight while others rather gorge themselves whenever the chance arises and so feed rather irregularly but in larger amounts [26]. As a consequence of eating, their center of gravity shifts accordingly. Probably the most important factor affecting a shark's buoyancy and its center of gravity is its liver where most of the fatty substances, especially squalene, are stored $[11,27]$. Squalene has a specific gravity of 0.855 thus is lighter than water. From this viewpoint, digestive gases could have a lesser impact, but considering that overall buoyancy is most stable when the gastric system is empty, food intake of any proportion affects buoyancy and the animal's center of gravity.

It has been suggested that white sharks, Carcharodon carcharias, prefer fatty food sources due to their energetic advantages [28]. However, there is also the possibility that fat is at least partially sought after in foods for the purpose of buoyancy, especially liver storage. Thus, the center of gravity would not just be influenced by the food intake and the production of digestive gases, but also by the actual storage of fatty substances in their livers. The center of gravity of the shark is affected on many levels and on a continu- ous basis. This raises the question of whether sharks can actively manipulate their centers of gravity, at least marginally or indirectly, through various strategies including regulation of the digestive tract. The ability to slow or accelerate digestion would help to better control buoyancy.

\section{Internal transport of digestive gases}

The amount of digestive gases produced from a single piece of prey largely depends on the ratio between proteins, fats, bones and other constituents of it, and how completely these different components can be broken down. Assuming that gas production occurs in the stomach as well as the intestines in sharks, it will accumulate in both areas. This raises the question of whether digestive gases can be actively transported through the digestive system or whether their site of accumulation purely depends on the tilt angle of the shark's body, and thus moves passively. The ability to actively move digestive gases would be advantageous. This would require the control over distinct sphincter muscles, as well as the stomach and intestine walls along the intestinal tract. Although a definite answer cannot be given, considering that sharks often change water depths, mixed with ongoing production of digestive gases and thus a change in buoyancy and center of gravity, voluntary control over some parts of the digestive system seems rather likely. However, should gas expansion require a rapid reduction in pressure e.g., when ascending rapidly as shown here, the increase in volume of digestive gases, and the resulting change in pressure, may force the respective sphincter muscles to open without any voluntary involvement?

\section{Conclusion}

Digestive gases, released through the oral and anal cavities of a shark, move around the stomach and intestines. Reducing water pressure or increasing temperature expands the volume of those gases to the point where it can create positive buoyancy, and therefore a release may be necessary. Freeing excessive gases through the oral or anal opening might reflect an active mechanism but it could also merely be the effect of increased gas pressure against the seal of the respective sphincter muscles.

\section{Acknowledgements}

I thank Shane Coote for allowing me to use his video clip on tiger shark gas release..

\section{References}

1. Brown RS, Colotelo, AH, Pflugrath BD, Boys CA, Lee J, et al. (2014) Understanding barotraumas in fish passing hydro structures: a global strategy for sustainable development of water resources. Fisheries 39 : 108-122.

2. Brown RS, Pflugrath BD, Colotelo AH, Brauner CJ, Carlson TJ, et al. (2012) Pathways of barotrauma in juvenile salmonids exposed to simulated hydroturbine passage: Boyle's law vs. Henry's law. Fisheries 121-122: 43-50.

3. Sundnes G, Bratland P (1972) Notes on the gas content and neutral buoyancy in physostome fish. Fisk Dir Skr Ser Hav Under 16(3): 89-97.

4. Leigh SC, Papastamatiou Y, German DP (2017) The nutritional physiology of sharks. Rev Fish Biol Fisheries 27(3): 561-585. 
5. Ballantyne JS, Shadwick RE, Farrell AP, Brauner CJ (2016) Physiology of elasmobranch fishes: internal processes. (1 ${ }^{\text {st }}$ edn), Academic Press, USA, pp. 395-456.

6. Beckmann CL, Mitchell JG, Seuront L, Stone DA, Huveneers C (2013) Experimental evaluation of fatty acid profiles as a technique to determine dietary composition in benthic elasmobranchs. Physiol Biochem Zool 86(2): 266-278.

7. Meyer CG, Holland KN (2012) Autonomous measurement of ingestion and digestion processes in free-swimming sharks. J Exp Biol 215(21): 3681-3684.

8. Areitio MF, Smith JPS, Correira JPS (2001) Buoyancy compensation problems in a sandtiger shark, (Carcharias taurus, Rafinesque, 1810). Bulletin de l'Institut océanographique, Monaco 20(1): 185-190.

9. Hussain SM (1989) Buoyancy mechanism and density of the sand tiger shark, Eugomphodus taurus (Carcharias taurus). Indian J Fisheries 36(3): 266-268.

10. Ritter E (2014) Coasting of pelagic thresher sharks, Alopias pelagicus, in comparison to two other species of the same ecomorphotype, and the limitation of video capturing in natural settings. Environ Sci 2(1): 13-23.

11. Bakes MJ, Nichols PD (1995) Lipid, fatty acid and squalene composition of liver oil from six species of deep-sea sharks collected in southern australian waters. Comp Biochem Physiol Part B: Biochem Molec Biol 110(1): 267-275

12. Wetherbee B, Gruber S, Ramsey A (1987) X-radiographic observations of food passage through digestive tracts of lemon sharks. Trans Am Fish Soc 116(5): 763-767.

13. Cortés E, Papastamatiou Y, Carlson J, Ferry-Graham L, Wetherbee B, et al. (2008) An overview of the feeding ecology and physiology of shark fishes. Papastamatiou Y, Carlson J, Ferry-Graham L, Wetherbee B, et al. (2008) An overview of the feeding ecology and physiology of shark fishes. In: Cyrino JEP, Bureau DB, Kapoor BG (Eds.) Feeding and digestive functions of fishes. Science Publishers, Jersey 393-443.

14. Armstrong JB, Schindler DE (2011) Excess digestive capacity in predators reflects a life of feast and famine. Nature 476(7358): 84-87.

15. Bucking C (2015) Feeding and digestion in elasmobranchs: tying diet and physiology together. In: Shadwick RE, Farrell AP, Brauner CJ (Eds.) Physiology of elasmobranch fishes: structure and interaction with environment. Elsevier, London.

16. Fänge R, Grove D (1979) Digestion. In: Hoar WS, Randall DJ, Brett JR (Eds.), Fish physiology. New York, USA.
17. He E, Wurtsbaugh WA (1993) An empirical model of gastric evacuation rates for fish and an analysis of digestion in piscivorous brown trout. Trans Amer Fish Soc 122: 717-730.

18. Compagno JVL (1984) An annotated and illustrated catalogue of shark species known to date. Food and Agriculture Organization of the United Nations 4(2): 36-65.

19. Bromley PJ (1994) The role of gastric evacuation experiments in quantifying the feeding rates of predatory fish. Rev Fish Biol Fisheries $4(1): 36-66$.

20. Dos Santos J, Jobling M (1991) Factors affecting gastric evacuation in cod, Gadus morhua L, fed single-meals of natural prey. J Fish Biol 38(5): 697-713.

21. Motta PJ, Wilga CAD (1995) Anatomy of the feeding apparatus of the lemon shark, Negaprion brevirostris. J Morphol 226(3): 309-329.

22. Holmgren S, Nilsson S (1999) Digestive system. In: Hamlett WC (Ed.), Sharks, skates, and rays: the biology of shark fishes. The Johns Hopkins University Press, Baltimore, Maryland, USA, pp. 144-173.

23. Jhaveri P, Papastamatiou Y, German DP (2015) Digestive enzyme activities in the guts of bonnethead sharks (Sphyrna tiburo) provide insight into their digestive strategy and evidence for microbial digestion in their hindguts. Comp Biochem Physiol A 189: 76-83.

24. Clarke A, Doherty N, DeVries AL, Eastman JT (1984) Lipid content and composition of three species of Antarctic fish in relation to buoyancy. Polar Biol 3(2): 77-83.

25. Van Vleet ES, Candileri S, McNeillie J, Reinhardt SB, Conkright ME (1984) Neutral lipid components of eleven species of Caribbean sharks. Comp Biochem Physiol B 79(4): 549-554.

26. Cortés E, Gruber SH (1990) Diet, feeding habits and estimates of daily ration of young lemon sharks, Negaprion brevirostris (Poey). Copeia 1990(1): 204-218.

27. Navarro-Garcia G, Pacheco-Aguilar R, Vallejo-Cordova B, Ramirez-Suarez JC, Bolaños A (2000) Lipid composition of the liver oil of shark species from the Caribbean and Gulf of California waters. J Food Compos Anal 13(5): 791-798

28. Klimley AP, Le Boeuf BJ, Cantara KM, Richert JE, Davis SF, et al. (2001) The hunting strategy of white sharks (Carcharodon carcharias) near a seal colony. Mar Biol 138: 617-636.
Creative Commons Attribution 4.0 International License

For possible submissions Click Here

\section{Submit Article}

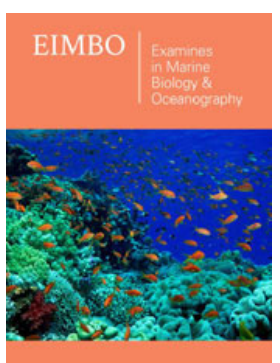

Examines in Marine Biology \& Oceanography

\section{Benefits of Publishing with us}

- High-level peer review and editorial services

- Freely accessible online immediately upon publication

- Authors retain the copyright to their work

- Licensing it under a Creative Commons license

- Visibility through different online platforms 